\title{
Principles of venovenous extracorporeal membrane oxygenation
}

\author{
Ming-Sing Si, MD
}

\footnotetext{
From the Section of Pediatric Cardiovascular Surgery, Department of Cardiac Surgery, University of Michigan, Ann Arbor, Mich.

Disclosures: Author has nothing to disclose with regard to commercial support.

Received for publication Oct 31, 2016; accepted for publication Oct 31, 2016; available ahead of print Dec 1, 2016.

Address for reprints: Ming-Sing Si, MD, 11-735 C.S. Mott Children's Hospital, SPC 4204, 1540 E Hospital Dr, Ann Arbor, MI 48109-4204 (E-mail: mingsing@umich.edu).

J Thorac Cardiovasc Surg 2017;153:e53-4

$0022-5223 / \$ 36.00$

Copyright (c) 2016 by The American Association for Thoracic Surgery

http://dx.doi.org/10.1016/j.jtcvs.2016.10.073
}

A review of history reveals that the development of extracorporeal membrane oxygenation (ECMO) closely followed that of cardiopulmonary bypass. In 1972, Hill and colleagues $^{1}$ were the first to describe the successful use of ECMO in a patient with trauma who had respiratory failure develop after repair of a blunt aortic injury. These pioneers used partial venoarterial (VA) ECMO to support this patient, although they had also described the preclinical and clinical use of venovenous (VV) ECMO in earlier reports. ${ }^{2,3}$

The contemporary experience with both VV and VA ECMO was recently reviewed by Squiers and colleagues ${ }^{4}$ in this Journal. VV ECMO has become an important therapy for severe respiratory failure in adults. In this issue of the Journal, Malik and colleagues ${ }^{5}$ introduce a novel variation of VV ECMO: the addition of an independent, parallel circuit. They first attempted support with a single VV ECMO circuit. Their initial cannulation strategy included a drainage cannula positioned in the inferior vena cava (IVC). VV ECMO output was infused through a cannula that was placed through the right internal jugular vein with its tip positioned within the right atrium. The patient had a high cardiac output state develop, however, and became persistently hypoxemic despite increasing ECMO flow and ensuring the lack of significant recirculation and oxygenator malfunction.

For this reason, Malik and colleagues ${ }^{5}$ placed a second VV ECMO circuit with a contralateral femoral drainage cannula along with an infusion cannula placed in the left subclavian vein with the tip positioned near the superior vena cava (SVC). With these dual circuits, total flows as great as $9 \mathrm{~L} / \mathrm{min}$ were achieved, with improvements in arterial blood oxygen saturation. The patient eventually had conversion back to a single circuit and then successfully weaned from ECMO.

It is quite remarkable that an additional circuit was needed to achieve adequate oxygenation, and a review of the literature indicates that this is possibly a seminal description of such a strategy. Hypoxemia during venovenous

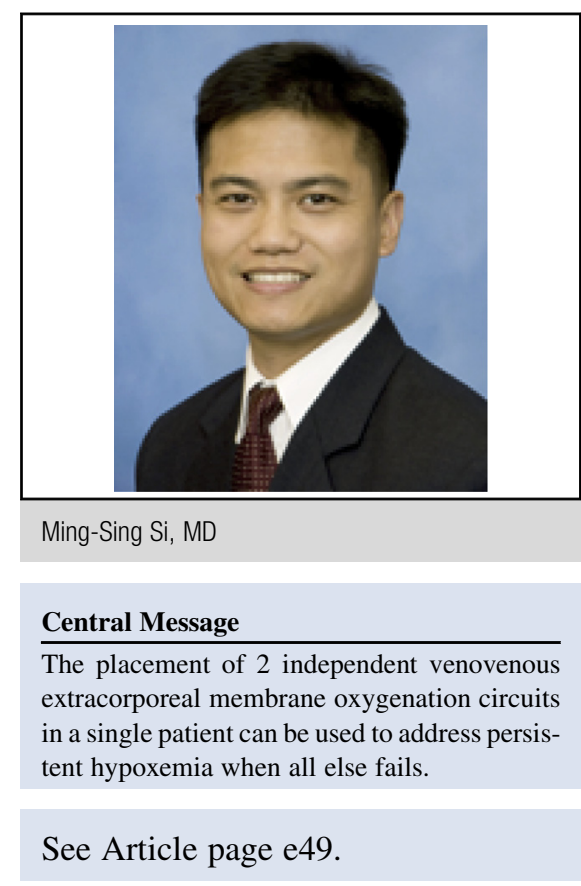

ECMO has been specifically addressed before. ${ }^{6,7}$ Nunes and colleagues ${ }^{7}$ recommended increasing ECMO flow, eliminating recirculation, optimizing pulmonary function, increasing serum hemoglobin concentration, ensuring proper oxygenator function, and optimizing the ratio of ECMO flow to native cardiac output.

If we make 3 reasonable assumptions, that intrinsic lung function is poor and does not contribute to oxygenation, that there are no intracardiac or extracardiac shunts, and that there is negligible bronchial artery blood flow, then we can deduce that the blood that is ejected into the systemic circulation is derived from what is ejected by the right ventricle. In the patient with VV ECMO support, the right ventricle receives blood from 3 sources: (1) net VV ECMO output flow, (2) total systemic venous return not captured by VV ECMO drainage cannulas, and (3) cardiac venous flow. The magnitude of the flow rate and oxygen saturation of each source affects the oxygenation of the total mixture of all of them (ie, what is ejected systemically). We can further define each of these sources by the following equations:

Net VV ECMO output flow

$=$ Total VV ECMO output - Recirculation shunt 
Total undrained systemic venous flow

$$
=\text { Undrained SVC flow }+ \text { Undrained IVC flow }
$$

$$
\begin{aligned}
& \text { Cardiac venous flow } \\
& =\text { Coronary sinus flow }+ \text { Thebesian vein flow }
\end{aligned}
$$

Considering these in more detail, we can understand the rationale behind the recommendations of Nunes and colleagues. ${ }^{7}$ For net VV ECMO output flow [1], proper positioning of drainage and infusion cannulas is important to eliminate a recirculation shunt. Assuming poor lung function, net VV ECMO output flow provides the oxygen to be delivered to the body. In the case of oxygenator malfunction, the low oxygen content of the blood in the net $\mathrm{VV}$ ECMO output flow then becomes an important reason for hypoxemia. With respect to total undrained systemic venous flow, in the described case, ${ }^{5}$ the SVC was left undrained. Certainly, as much as $35 \%$ of cardiac output returns through the SVC in adults, which may be a source of significant deoxygenated blood. ${ }^{8}$ In addition, the described patient ${ }^{5}$ had high cardiac output develop, and thus the amount of undrained IVC flow likely surpassed the drainage capacity of the cannula or may have surpassed drainage capacity because ECMO pump flows were set at lower values than the intrinsic cardiac output. Increasing VV ECMO pump flows thus may decrease the total undrained systemic venous flow [2] while increasing the net VV ECMO output flow [1]. Finally, cardiac venous flow [3] is generally considered to comprise a negligible portion of cardiac output $(3 \%)$. In cases of persistent left SVC draining into the coronary sinus, however, this source of systemic venous blood flow can be significant and thus can't be ignored.

In essence, hypoxemia in the patient supported by $\mathrm{VV}$ ECMO can be avoided by maximizing net VV ECMO output flow [1] and minimizing total undrained systemic venous return [2]. Sometimes it is not possible to capture all sources of systemic venous return because of difficult vascular access and anatomy, or the addition of an addi- tional cannula is felt to be prohibitively risky. In such cases, acceptance of mixing a substantial amount of total undrained systemic venous return [2] with net VV ECMO output flow [1] will occur. In this instance, however, increasing the serum hemoglobin concentration to increase the total oxygen carry capacity of the circulating blood is an important and effective maneuver.

Where does adding a second VV ECMO circuit fit in the context of this framework? Certainly, the placement of additional venous drainage cannulas will decrease total undrained systemic venous flow [2]. The second pump would provide additional flow, and assuming that there was negligible recirculation, this resulted in an increased net VV ECMO output flow [1]. We thus could predict that this strategy would indeed be effective in increasing the patient's oxygen saturation. As Malik and colleagues ${ }^{5}$ themselves mention, however, adding additional venous cannulas and transfusing blood to increase the serum hemoglobin concentration would be the preferred first steps to take.

\section{References}

1. Hill JD, O'Brien TG, Murray JJ, Dontigny L, Bramson ML, Osborn JJ, et al. Prolonged extracorporeal oxygenation for acute post-traumatic respiratory failure (shock-lung syndrome). Use of the Bramson membrane lung. N Engl J Med. 1972; 286:629-34.

2. Hill JD, Bramson ML, Rapaport E, Scheinman M, Osborn JJ, Gerbode F. Experimental and clinical experiences with prolonged oxygenation and assisted circulation. Ann Surg. 1969;170:448-59.

3. Hill JD, Bramson ML, Hackel A, Deal CW, Sanchez PA, Osborn JJ, et al. Laboratory and clinical studies during prolonged partial extracorporeal circulation using the Bramson membrane lung. Circulation. 1968;37(4 Suppl):II139-45.

4. Squiers JJ, Lima B, DiMaio JM. Contemporary extracorporeal membrane oxygenation therapy in adults: fundamental principles and systematic review of the evidence. J Thorac Cardiovasc Surg. 2016;152:20-32.

5. Malik A, Shears LL, Zubkus D, Kaczorowski DJ. Paralell circuits for refractory hypoxemia on venovenous extracorporeal membrane oxygenation. J Thorac Cardiovasc Surg. 2017;153:e49-51.

6. Aokage T, Palmér K, Ichiba S, Takeda S. Extracorporeal membrane oxygenation for acute respiratory distress syndrome. J Intensive Care. 2015;3:17.

7. Nunes LB, Mendes PV, Hirota AS, Barbosa EV, Maciel AT, Schettino GP, et al. Severe hypoxemia during veno-venous extracorporeal membrane oxygenation: exploring the limits of extracorporeal respiratory support. Clinics (Sao Paulo). 2014;69:173-8.

8. Mohiaddin RH, Wann SL, Underwood R, Firmin DN, Rees S, Longmore DB. Vena caval flow: assessment with cine MR velocity mapping. Radiology. 1990;177: $537-41$. 